\title{
Erratum to: Artery reopening is required for the neurorestorative effects of angiotensin modulation after experimental stroke
}

\author{
Ahmed Alhusban², Anna Kozak ${ }^{1}$, Wael Eldahshan ${ }^{1}$, Adviye Ergul ${ }^{1}$ and Susan C. Fagan ${ }^{1}$
}

\section{Erratum to: Exp \& Trans Stroke Med (2016) 8:4 \\ DOI 10.1186/s13231-016-0018-x}

After publication of the original article [1], the corresponding author noted that one of the author's names was spelt incorrectly. The correct name of the author (Wael Eldahshan) has been updated in the original article, and published in this Erratum for quick reference. We apologise for any confusion this may have caused.

\section{Author details}

${ }^{1}$ Charlie Norwood VA Medical Center, and Center for Pharmacy and Experimental Therapeutics, University of Georgia College of Pharmacy, and Georgia Regents University, Augusta, GA, USA. ${ }^{2}$ Clinical Pharmacy Department, College of Pharmacy, Jordan University of Science and Technology, P.O. Box 3030, Irbid 22110, Jordan.

The online version of the original article can be found under doi:10.1186/s13231-016-0018-x.

Received: 26 May 2016 Accepted: 26 May 2016

Published online: 14 June 2016

\section{Reference}

1. Alhusban A, Kozak A, Eldahshan W, Ergul A, Fagan SC. Artery reopening is required for the neurorestorative effects of angiotensin modulation after experimental stroke. Exp Trans Stroke Med. 2016;8:4.

\footnotetext{
*Correspondence: ayalhusban@just.edu.jo

${ }^{2}$ Clinical Pharmacy Department, College of Pharmacy, Jordan University

of Science and Technology, P.O. Box 3030, Irbid 22110, Jordan
} 